\title{
O GÊNIO EM NIETZSCHE
}

\author{
Erinaldo de Ol. Sales ${ }^{1}$
}

RESUMO: Este ensaio pretende abordar o gênio em Nietzsche, o que é o gênio e como ele se manifesta nos escritos desse filósofo. Para tanto, partir-se-á das anotações dos fragmentos póstumos do filósofo, num percurso inverso, até os livros éditos, muito embora a maior produção filosófica de Nietzsche, por assim dizer, dá-se justamente nos escritos que ele não publicou em vida, e sim nos agora conhecidos fragmentos póstumos.

PALAVRAS-CHAVE: Nietzsche, gênio, Kant.

\section{INTRODUÇÃO}

Kant, o grande 'inspirador' dos românticos do período posterior a ele, trata do gênio no parágrafo 46 da Crítica do Juízo, (no capítulo 'Bela arte é a arte do gênio') e apresenta duas definições de gênio: (1) "Gênio é o talento (dom natural) que dá à arte a regra", e (2) "Gênio é a disposição natural inata (ingenium) pela qual a natureza dá à arte à regra" (Kant: 1980, p.246).

Existem duas características básicas do gênio: talento e disposição naturais daquele que cria uma obra de arte. Kant afirma que a definição de gênio que propõe é arbitrária, pois se adéqua ao que é vinculado geralmente à palavra gênio, no entanto, as belas-artes são necessariamente obras do gênio. Ainda, 'arte pressupõe regras', pois só assim um produto com pretensões artísticas pode ser representado como possível. Não é qualquer regra que permite um conceito de bela-arte, já que esta não pode inventar a regra para si própria. Sem uma regra prévia, não se pode chamar de arte um produto. Quem definirá estas regras ao produto, a fim de que este alcance o status de arte, é o sujeito com a disposição de suas próprias faculdades dá regras à arte, ou seja, que o gênio crie as regras prévias para elevar o produto feito ao patamar da bela-arte.

A partir disto, Kant especifica o que é o gênio:

1) é um talento, de produzir aquilo para o qual não se pode dar nenhuma regra determinada: não disposição de habilidade para aquilo que pode ser apreendido segundo alguma regra; consequentemente, que originalidade tem de ser sua primeira propriedade. 2) Que, como também pode haver insensatez original, seus produtos têm de ser ao

\footnotetext{
${ }^{1}$ Erinaldo de O. Sales é doutorando em Arquitetura e Urbanismo pela FAU-UnB. 
ERINALDO DE OL. SALES

\begin{abstract}
mesmo tempo modelos, isto é, exemplares; portanto, eles mesmos não provindo de imitação, têm de servir, no entanto, a outros para isso, isto é, como justa-medida ou regra do julgamento. 3) que ele mesmo não pode descrever ou indicar cientificamente como institui seu produto, mas que é como natureza que ele dá a regra; e, por isso, o criador de um produto, que ele deve a seu gênio, não sabe, ele mesmo, como se encontram nela as idéias para isso, e também não está em seu poder inventá-las à vontade ou conforme um plano, e comunicá-las a outros em prescrições tais, que os ponham em situação de criar produtos equivalentes (...). 4) Que a natureza, pelo gênio, prescreve, não à ciência, mas à arte a regra; e também isto somente na medida em que esta última deve ser bela-arte. (1980, p.246)
\end{abstract}

No parágrafo 47, Kant vem elucidar e explicitar as afirmações anteriores sobre o gênio que deve ser o oposto do espírito de imitação, aquele que tem a capacidade de imitar não pode ser considerado como gênio. Quem pensa ou inventa por si mesmo ou quem descobre algo novo para a arte ou a ciência ainda não é o fundamento para se ter, nestas, uma cabeça de gênio. Para explicitar, dá o exemplo de Newton. Mesmo os princípios da filosofia natural que Newton expôs, "por mais poderosa cabeça que seja requerida para inventar tais princípios" (Kant: 1980, p.247), Kant acha que qualquer pessoa pode aprender. Por outro lado, não se aprende a fazer poemas com espírito, mesmo tendo lido ou estudado todas as prescrições da arte poética, e mesmo estas tendo modelos excelentes. E Kant explica o motivo: os passos dados por Newton são inteiramente claros, podendo ser repassados e demonstrados aos sucessores. O que não acontece com Homero ou Wieland (poeta alemão contemporâneo de Kant), já que não se sabe e não se pode demonstrar e nem ensinar o que se passa na cabeça de um poeta, quais os elementos que se reúnem aí para originar o poema. Com isto, Kant distingue especificamente o grande descobridor (Newton) daquele dotado pela natureza à belaarte (Homero), este seria merecedor da honra de ser chamado de gênio no entendimento de Kant.

No parágrafo 49 da Crítica do juízo, após desenvolver a argumentação sobre as faculdades da mente que constituem o gênio por meio do princípio que 'vivifica a alma', ou seja, a faculdade de exposição de Idéias estéticas, Kant diz que os poderes-damente que constituem o gênio são a imaginação e entendimento. Após desenvolver cada um desses 'poderes-da-mente', chega-se aquilo que se denomina gênio:

$1^{\mathrm{o}}$ - Um talento voltado para a arte e não para a ciência;

$2^{\circ}$ - Como talento artístico, pressupõe-se um conceito determinado do produto, como um fim (entendimento) e uma representação da matéria (intuição), ou seja, uma 'proporção da imaginação ao entendimento'; 
ERINALDO DE OL. SALES

$3^{\text {o }}$ - Na exposição de Idéias estéticas, o gênio tem rica matéria para que possa representar a imaginação com toda liberdade e espaço para seguir a direção de todas as regras, tendo como objetivo final a exposição do conceito dado;

$4^{\text {o }}$ - Finalidade não intencional, não procurada; liberdade de concordância da imaginação com a legalidade do entendimento, não encontrada em nenhuma regra científica ou imitação mecânica, pois somente é produzida pela natureza do gênio.

Dessa forma, pode-se caracterizar o gênio para Kant resumido em quatro características:

1) Deve ser original, uma vez que o gênio é o talento para produzir aquilo que não se pode oferecer regra nenhuma;

2) O gênio deve servir aos outros como medida, muito embora ele não tenha surgido por imitação;

3) O gênio não pode indicar ou descrever como ele realiza sua produção;

4) A natureza deve oferecer ao gênio a regra para a arte, e não para a ciência.

\section{O GÊNIO EM NIETZSCHE}

Nietzsche, em seus escritos, abordou os temas mais caros da filosofia, da religião, da arte, entre outros. E não poderia ter deixado de tratar da questão do gênio. Termo de longa trajetória na tradição filosófica, desde a antiguidade. O estudo desse termo tem uma grande ênfase no século XVIII, como os românticos alemães, e ponto comum também de Nietzsche, os quais, por sua vez, partiram todos de Kant, que também influenciou autores como Goethe e Schelling.

Fazendo o percurso inverso, buscamos o que seria o gênio para Nietzsche nos seus fragmentos, escritos bem mais extensos do que as obras consagradas do filosofo: "O que é gênio? Querer um objetivo elevado $e$ os meios para tanto" (Nietzsche: 2004, p.265) Ou "Gênio": será que viveu alguma vez um ser-acima-do-humano?" (idem, p.291).

É importante destacar esse questionamento de Nietzsche, porque em alguns momentos pode se ver ele mesmo como uma encarnação do gênio, ou próximo do gênio: 
ERINALDO DE OL. SALES

25 (9)

É claro e evidente que eu conheço tudo aquilo que se chama de sofrimentos do gênio: ser ignorado, ser deixado de lado, as superficialidades de todo grau, as superstições, as sacanagens; eu sei como alguns acreditam estar fazendo algo bom para nós quando tentam nos levar para situações "mais cômodas", entre pessoas ordeiras e confiáveis, eu tenho admirado o inconsciente instinto da destruição que torna a medianidade mobilizada entre nós, e isso com a melhor crença em ter direito a tanto. (...) (2008, p.4)

Os gênios são formados por antíteses:

25 (202)

As antíteses copulando feito macho e fêmea para gerar Algo Terceiro gênese das obras dos gênios! (idem, p.51)

Um dos problemas do gênio é

Mais um Problema da Dieta. - Os meios através dos quais Júlio César se defendia contra doenças e dores de cabeça: marchas gigantescas, o modo de vida mais simples, permanência ininterrupta em um espaço aberto, fadigas constantes. - Tomando por alto, estas são as punições em geral estabelecidas em função da conservação e da proteção contra a extrema vulnerabilidade daquela máquina sutil que trabalha sob a mais elevada pressão e que se chama gênio. - (2001c, p.32)

Para o filósofo: $O$ "gênio" é a máquina mais sublime que existe, - e por isso mesmo a mais frágil.(in Vontade de potência).

Ou então, na obra com o mesmo título:

183.

A grande moedagem falsa niilista com hábil abuso dos valores morais:

a) o amor considerado como despojamento da personalidade: da mesma forma a compaixão;

b) somente o intelecto, despojado de sua personalidade ("o filósofo") conhece a verdade, "o ser" verdadeiro e a essência verdadeira das coisas;

c) o gênio, os grandes homens são grandes porque não buscam nem a si mesmos nem sua razão de ser: o valor do homem cresce na proporção que nega a si mesmo; [destaque meu] 
ERINALDO DE OL. SALES

No livro Além do bem e do mal (2005a), ele assim se expressa quanto ao gênio: 74. Um homem dotado de gênio é insuportável se além disso não tem pelo menos duas outras qualidades: a gratidão e a polidez (p.63), ou no fragmento 151. Não basta ter gênio, é preciso também ter permissão de tê-lo — que lhes parece, meus amigos? (p.70)

Mais adiante, ainda no Além do bem e do mal (2005), pode-se ler:

\section{6}

Frente a um homem de gênio, isto é, um ser que cria ou fecunda, estas duas expressões tomadas em seu sentido mais lato, o homem de ciência, o douto, tem sempre em si algo da solteirona, uma vez que exatamente como esta não tem a menor idéia destas duas funções, as mais importantes do homem. De fato, ambos, tanto a solteirona quanto os doutos, são respeitáveis, à guisa de compensação, e em tais casos também se a sublinha, mostrando um certo despeito ao se sentir obrigado a fazer uma tal concessão.

Para Nietzsche, há duas espécies de gênio:

248

um que gera e quer gerar, e outro que quer ser fecundado e parir. Entre os povos de gênio alguns receberam a incumbência do problema feminino da gravidez e do trabalho secreto de formar, amadurecer, aperfeiçoar - desta espécie foram os gregos e também os franceses -; os outros são destinados a fecundar e serem a causa de novas ordens de vida - como os judeus, os romanos e talvez também, com toda modéstia, os alemães? povos dilacerados e extasiados por febres ignotas $e$ impulsos irresistiveis fora de seu ser, enamorados e cúpidos por raças estrangeiras (daquelas que se deixam fecundar) e ao mesmo tempo despótico, como tudo aquilo que sente em si a exuberância da força que "fecunda", a "graça de Deus". Estas duas espécies de gênio se procuram, como o macho procura a fêmea, mas não sabem entender-se entre si, como acontece entre macho e fêmea. (idem, p.141)

Nesses fragmentos, Nietzsche traça uma série de distinções quanto ao gênio e os possíveis "candidatos" a esse patamar, como no problema que ele coloca no fragmento abaixo:

$35(25)$

Problema: muitas espécies de grandes homens talvez não sejam mais possíveis. P. ex., o santo. Talvez também o filósofo. Enfim, o gênio? (...) (2008, p.450) 
ERINALDO DE OL. SALES

Ou então:

25 (278)

Os maus, esses são especificamente para mim os que dão a reis etc. a falsa imagem do ser humano mais poderoso, baseados no poder de exércitos, funcionários (mesmo do gênio sem perfeição interior, como Frederico, o Grande, e Napoleão), deixando aflorar a questão: para quê? (idem, p.65)

Também questiona a eliminação do gênio, bem como o "ser humano religioso" para se obter saúde:

$25(35)$

Caso se quisesse saúde, então se eliminaria o gênio. Igualmente o ser humano religioso. Caso se quisesse moralidade, igualmente: eliminação do gênio. (idem, p.11)

Alguns "candidatos":

25 (259)

Que se cometam e se agüentem muitas ações ruins, mantendo-se de pé pela grandeza de um modo de pensar que não se sinta temor diante da condenação da fama - uma firmeza e uma grandeza originais, desconsiderando-se juízes de valor que foram aprendidos. (Em Rée faltam todos os seres humanos originais)

Caracterizar Bismarck.

Do mesmo modo Napoleão - uma sensação de bem-estar sem igual percorreu a Europa: o gênio deve ser senhor, o "príncipe" idiota de outrora aparecia como caricatura. - Somente os mais burros faziam oposição, ou aqueles que tinham maior desvantagem com ele (Inglaterra)

Não se entendem grandes homens: eles se perdoam qualquer crime, mas nenhuma fraqueza. Quantos eles matam! Todo gênio - quão deserto existem em torno dele! (idem, p.62)

Ou:

$26(420)$

Em tudo o que Goethe fez, diz Mérimée, há uma mistura de gênio e de idiotia teuta (bom! Isso é bem alemão!): "será que ele está gozando consigo mesmo ou com os outros?" - Wilhelm Meister: as mais belas coisas do mundo se alternando com infantilidades as mais ridículas. (idem, p.221) 


\section{ERINALDO DE OL. SALES}

Nietzsche não poupa ninguém, seja Wagner ou Schopenhauer:

$34(151)$

Sobre o "gênio". Quão pouco talento, p. ex., em R[ichard] W[agner]! Será que já houve alguma vez um músico que, aos 28 anos de idade, fosse tão pobre (não tão pouco desenvolvido, tão pouco esclarecido, mas tão pobre) a ponto de ficar com inveja de Meyerbeer - invejoso a tal ponto que fosse capaz de se incomodar a vida inteira em relação a isso? para, por via de conseqüência, com o rigor das "almas belas", continuar rancoroso contra ele por toda a sua vida? Por outro lado, vê-se como Kant, com toda razão, elogia o esforço diligente e a persistência como aquilo que etc. (idem, p.409)

Ainda sobre Wagner, (em Vontade de potência):

\section{1.}

Se num artista entende-se por gênio a maior liberdade, sob a égide da lei, a leveza divina, a frivolidade no que há de mais difícil, Offenbach tem muito mais direito de ser chamado "gênio" que Richard Wagner. Wagner é pesado, maciço; nada lhe é mais estranho que os momentos de perfeição travessa, tais como o polichinelo de Offenbach os atinge, cinco, seis vezes em quase todas as suas "buffonneries". Mas, talvez, por gênio, é mister entender-se outra coisa.

Sobre Schopenhauer (também em Vontade de potência):

420.

Schopenhauer interpretou a intelectualidade superior como uma separação da vontade: não quis ver na libertação dos preconceitos morais, que é própria do grande espírito que se liberta das algemas, a imoralidade típica do gênio; artificialmente só fixou o que venerava unicamente, o valor moral da "renúncia", como condição da atividade intelectual, perspectivas "objetivas". A "verdade", até na arte, apresenta-se depois da supressão da vontade...

Através de todas as idiossincrasias morais, vejo uma avaliação fundamentalmente diferente: não conheço essas separações absurdas entre o gênio e o mundo da vontade moral e imoral. O homem moral é de uma espécie inferior ao homem imoral, de uma espécie mais fraca; é um tipo segundo a moral, não é porém seu próprio tipo; é uma cópia, uma boa cópia ao rigor, - a medida de seu valor reside fora dele. Estimo o homem pela quantidade de potência e pela plenitude de sua vontade; e não conforme o enfraquecimento e a purificação da vontade; considero uma filosofia que ensina a negação da vontade como uma doutrina de aviltamento e de calúnia... Julgo a potência de uma vontade segundo o 
ERINALDO DE OL. SALES

grau de resistência, de dor, de tortura que ela suporta para convertê-las em seu favor; não censuro à existência seu caráter mau e doloroso, mas espero que esse caráter se tornará um dia mais mau e mais doloroso ainda...

Ou no fragmento abaixo:

$25(11)$

... ele [Schopenhauer] jamais conseguiu transformar isso [a questão do pessimismo] suficientemente em palavras, graças àquela boba superstição do gênio que ele havia aprendido dos românticos, e graças à sua vaidade, que o obrigou a ficar sentado um cima de uma filosofia que tinha se originado de seu $26^{\circ}$ ano de vida e que também é própria de tal época da vida - como todos nós lá do fundo bem sabemos, não é verdade, meus amigos? (2008, p.5)

E arremata, quanto a Schopenhauer:

34 (117)

NB. Schopenhauer, seduzido em sua juventude pelos românticos, e desviado de seus melhores instintos, era no fundo um voltairiano da cabeça aos pés e bem um filho do século passado - de resto também levado para além do gosto francês por meio dos gregos e de Goethe, e sobretudo - ele não era um teólogo! A "imutabilidade do caráter", em alemão talvez a preguiça, e além disso a crença na infalibilidade do gênio (em alemão, talvez a vaidade) levaram-no apressadamente a declarar sagrado o seu "pecado de juventude", quero dizer, a sua metafísica da vontade; e a não se "desenvolver" mais. Um ser humano com o talento dele tinha na cabeça o material para cinco sistemas melhores, e cada um mais verdadeiro e mais falso que os demais. (idem, p.398)

Ainda há outros:

34 (45)

Baudelaire, de gosto alemão, se algum parisiense pode chegar a têe-lo, sente à maneira teuta ao não suportar Victor Hugo, chamando-o de um “asno com gênio". (idem, p.376)

Quanto ao gênio nacional, ele escreve, em Vontade de potência: 
ERINALDO DE OL. SALES

Para a característica do GÊENIO NACIONAL, em relação ao que lhe é estranho e atribuído:

O gênio inglês torna tudo quanto recebe mais grosseiro e mais natural.

O gênio francês dilui, simplifica, logiciza, enfeita.

O gênio alemão embrulha, transmite, confunde, moraliza

E continua:

60.

A separação entre o "público" e o "cenáculo" —: para o primeiro, é preciso ser-se hoje charlatão;

no segundo, querem um "virtuose" e nada mais! Os gênios específicos deste século venceram esta separação e foram grandes nos dois domínios; o grande charlatanismo de Vitor Hugo e Richard Wagner, a par de verdadeiro virtuosismo, permitiu-lhes satisfazer aos mais requintados sob o ângulo da arte. Daí a falta de valor: têm uma ótica variável, quer dirigida para as necessidades mais grosseiras, quer para as mais requintadas.

Por fim:

256

Todos os trabalhos secretos da alma dos homens mais profundos e de maior amplitude de visão tendiam a preparar tal síntese e procurar antecipar o europeu do futuro, sobretudo na aparência ou ainda nas horas de fraqueza e na velhice lutaram pelo princípio da "nacionalidade" - e repousaram de si mesmos tornando-se "patriotas". $O$ meu pensamento lembra os homens que tiveram renome: Napoleão, Goethe, Beethoven, Stendhal, Heinrich Heine, Schopenhauer. Não incorrerei em reprovação se a estes nomes eu juntar o de Richard Wagner, acerca do qual não é preciso deixar-se induzir a formar um falso conceito sobre a base de seus próprios mal-entendidos - gênios de sua espécie raramente têm o direito de entender a si mesmos. Ainda menos se deve considerar o caso trivial que se faz na França contra ele - é um fato incontestável que entre o neo-romantismo francês e Richard Wagner há uma íntima afinidade. (2005a, p.149)

Em outro fragmento, ele compara o estado de gênio com a neurose, como, p. ex., em: 253. (...) 9. problema da 'saúde' e da 'histeria' - Gênio = neurose (2007, p.129). Embora, em outro momento, ele diga, ainda na compilação Vontade de potência:

358.

Da mesma forma que seria permitido hoje considerar o "gênio" como uma forma de neurose, poder-se-ia talvez fazer o mesmo da potência 
ERINALDO DE OL. SALES

sugestiva artística, - e, realmente, nossos artistas são apenas parentes bem próximos das mulherzinhas histéricas!!! Mas eis aqui um argumento contra o "hoje" e não contra os "artistas"...

Por que os fracos são vitoriosos

E prossegue:

389.

Em suma, os doentes e os fracos são mais compassivos, mais "humanos" —; têm mais espírito, são mais mutáveis, mais múltiplos, mais divertidos, - mais malignos; foram os doentes que inventaram a malignidade. (Uma precocidade doentia encontra-se muitas vezes entre os raquíticos, os escrofulosos e os tuberculosos. -) O espírito é próprio das raças tardias: os judeus, os franceses, os chineses. (Os anti-semitas não podem perdoar aos judeus o fato de terem espírito - e dinheiro. Anti-semita é um nome dos "fracassados".) Os doentes e os fracos têm a seu favor a fascinação, são mais interessantes que os bem saudáveis; o louco e o santo - as duas espécies de homens mais interessantes... estreitamente aparentadas com o "gênio".

Abordado também no personagem Zaratustra:

$31(2)$

(...)

No Zaratustra é necessário, portanto, abordar:

(...)

3) os solitários, os não-educados, os que-se-explicam-mal e degeneram, sendo sua degeneração sentida como fundamento contrário à sua existência ("neurose-do-gênio!”) (2008, p.307)

Pois 31 (6) o gênio vê Zaratustra como a corporificação do seu pensamento (idem, p.308) artística:

Para Nietzsche, a questão da genialidade está associada à da arte e da produção

256. Apenas como um gênio, no ato da produção artística, se misturado com o artista primordial do mundo, sabe algo da essência eterna da arte, pois é nesse estado parecia tão maravilhosa, assombrando a imagem da história que pode virar os olhos e olhar para si mesmo. Nesse momento é, simultaneamente, sujeito e objeto, poeta, ator e espectador. (NT, 5) (2007, p.133) 


\section{ERINALDO DE OL. SALES}

É no livro Humano, demasiado humano (2005b) que Nietzsche trata, mais enfaticamente, da questão do gênio ligado à arte, como nos fragmentos a seguir:

\section{7}

O gênio artístico quer proporcionar alegria, mas, se tiver num nível muito alto, provavelmente lhe faltarão os que a desfrutem; ele oferece manjares, mas não há que os queira. Isso lhe dá um pathos que às vezes é ridículo e tocante; pois no fundo ele não tem o direito de obrigar os homens ao prazer. Seu pífaro soa, mas ninguém quer dançar: pode isso ser trágico? - talvez. Enfim, para compensar essa privação ele tem mais prazer em criar do que o restante dos homens em todas as outras espécies de atividade. Seu sofrimento é sentido como exagerado, porque o seu tom de lamento é mais forte, e sua boca, mais eloqüente; em algumas ocasióes o seu sofrimento é de fato muito grande, mas apenas porque é grande sua ambição, sua inveja. O gênio do saber, como Kepler e Spinoza, em geral não é tão ávido, e não faz tamanho caso de seus sofrimentos e privações, na realidade maiores. Ele pode mais seguramente contar com a posteridade e se despojar do presente; enquanto um artista que faz o mesmo esta jogando um jogo desesperado, em que o seu coração padecerá. (p.111-2)

\section{2}

De onde vem a crença de que só no artista, no orador e no filósofo existe gênio? De que só eles têm intuição? (como o que lhe atribuímos uma espécie de lente maravilhosa, com a qual vêem diretamente a essência). Claramente, as pessoas falam de gênio apenas quando os efeitos do grande intelecto lhes agradam muito e também não desejam sentir inveja. Chamar alguém de "divino" significa dizer: "aqui não precisamos competir". E além disso: tudo o que esta completo $e$ consumado é admirado, tudo o que está vindo a ser é subestimado....A arte consumada da expressão rejeita todo pensamento sobre o devir; ela se impõe tiranicamente como perfeição atual. Por isto os artistas da expressão são vistos eminentemente como geniais, mas não os homens de ciência. Na verdade, aquela apreciação e esta subestimação não passa de uma infantilidade da razão. (p.115)

\section{3}

Só não falem de dons e talentos inatos. Podemos nomear grandes homens de toda espécie que foram pouco dotados. Mas adquiriram grandeza, tornaram-se gênios (como se diz) ... Todos tiveram a diligente seriedade do artesão, que primeiro apreende a construir perfeitamente as partes, antes de ousar fazer um grande todo; permitiram-se tempo para isso, porque tinham mais prazer em fazer bem o pequeno e o secundário do que no efeito de um todo deslumbrante. (p.116)

Finalmente, n'O livro do filósofo (2001b), Nietzsche escreve sobre a relação entre o gênio filosófico e a arte: 
48

Qual a relação entre o gênio filosófico e a arte? Da relação direta pouco se pode apreender. Devemos perguntar: o que é a arte, na filosofia? E a obra de arte? O que resta depois que seu sistema, enquanto ciência, é aniquilado? Ora, deve ser justamente este resíduo que domina o instinto do saber e, também, o que nele existe de artístico. Por que se necessita de tal freio? Porque, considerando do ponto de vista científico, é uma ilusão, uma inverdade, que ludibria o instinto do conhecimento e só provisoriamente o satisfaz. $O$ valor da filosofia nesta satisfação não corresponde à esfera do conhecimento, mas à esfera da vida, a vontade de existência usa a filosofia tendo por fim uma forma superior de existência. Não seria possível que arte e a filosofia se pudessem voltar contra a Vontade: a própria moral está a servi-la. A toda-poderosa Vontade. Uma das formas mais delicadas da existência, o Nirvana relativo. (p.13-4)

Em Humano, demasiado humano, no capítulo IV, ele trata "Da alma dos artistas e escritores", e a introdução do parágrafo 162 refere-se ao Culto do gênio por vaidade:

Porque pensamos bem de nós, mas no entanto esperamos de nós que possamos alguma vez fazer o esboço de uma pintura de Rafael ou uma cena tal como a de um drama de Shakespeare, persuadimo-nos de que a faculdade para isso é maravilhosa acima de todas as medidas, um raríssimo acaso, ou, se ainda temos sentimento religioso, uma graça do alto. Assim, nossa vaidade, nosso amor-próprio, propiciam o culto do gênio: pois somente quando este é pensado longe de nós, como um miraculum, ele não fere (...). (1983, p.104).

O gênio é também, para Nietzsche, um aprendiz, que nada faz senão "pôr, edificar e modelar pedras". E justifica a introdução do parágrafo:

Toda atividade do homem é complicada até o miraculoso, não somente a do gênio: mas nenhuma é um "milagre". - De onde então a crença de que somente em artistas, oradores e filósofos há gênio? de que somente eles têm "intuição"? (...) Os homens, evidentemente, só falam do gênio ali onde os efeitos do grande intelecto lhes são mais agradáveis, e eles, por sua vez, não querem sentir inveja. Denominar alguém "divino" quer dizer: "aqui não precisamos rivalizar". (idem, p.105)

No parágrafo 235 de Humano, demasiado humano, ao tratar, no capítulo V, dos "Sinais de cultura superior e inferior", Nietzsche o inicia da seguinte forma: 
ERINALDO DE OL. SALES

Gênio e Estado ideal em contradição - Os socialistas desejam instaurar um bom-viver para o maior número possível. Se a pátria duradoura desse bem-viver, o Estado perfeito, fosse efetivamente alcançada, então, por esse bem-viver, o chão de que cresce o grande intelecto, e em geral o indivíduo forte, estaria destruído: refiro-me à grande energia. A humanidade se teria tornado demasiado débil, se esse Estado tivesse sido alcançado, para poder ainda gerar o gênio. (idem, p.105)

Ou seja, um mundo perfeito — também para os socialistas — não mais poderia gerar o gênio.

Poderíamos ainda citar inúmeras passagens da obra de Nietzsche a respeito do gênio. No entanto, encerramos este nosso "mosaico de citações" com um fragmento de Aurora, no qual ele fala do "extravio moral do gênio":

53 6. O extravio moral do gênio - Numa certa categoria de grandes espíritos, podemos observar um espetáculo penoso e até certo ponto horrível: os seus momentos mais fecundos, os seus vôos em direcção aos cumes e às regiões mais distantes parecem não estar adaptados ao conjunto d sua constituição e ultrapassar as suas forças, residindo aí uma constante deficiência e, com o tempo, um defeito da máquina, que por seu lado, nas naturezas de uma tão alta intelectualidade, se traduz em todas as espécies de sintomas morais e intelectuais, muito mais do que em misérias físicas. Assim, o que há neles de inexplicavelmente ansioso, vaidoso, odioso, invejoso, constrangido e constrangedor e que brota subitamente para o exterior, todo o lado excessivamente pessoal, a falta de liberdade em naturezas como as de Rosseau e de Schopenhauer, podiam muito bem ser a seqüência de uma periódica doença do coração, sendo esta por seu turno, conseqüência de uma doença nervosa, e esta última conseqüência de... Na medida em que gênios nos habita, somos cheios de intrepidez, como loucos e não ligamos à vida, à saúde, à honra; sulcamos o dia num vôo mais livre que o da águia, e na escuridão estamos mais seguros do que o mocho. Mas o gênio abandona-nos subitamente, e não menos subitamente, um enorme cansaço abate-se sobre nós: já não nos compreendemos, sofremos com tudo o que não vivemos, estamos como no meio de rochedos nus, perante a tempestade, e ao mesmo tempo somos como lamentosas almas de criança que temem qualquer ruído ou sombra. - Três quartos do mal cometido no mundo acontecem por cansaço, e este é, antes de mais, um processo fisiológico. (s.d., p.232-3)

Dessa forma, pelo que foi apresentado nas passagens sobre o gênio, escritas por Nietzsche, percebe-se que o filósofo coloca a ideia de gênio para além de um simples ideal. Ele tenta destruir o ideal de gênio da tradição romântica e também - por que não? - da tradição metafísica, pois o gênio se torna essencial para a busca de si mesmo, e não mais como um ser excepcional, mas um indivíduo criativo e propenso a levar em conta esse caráter criativo para a sua vida. 
ERINALDO DE OL. SALES

No livro Crepúsculo dos ídolos, assim Nietzsche define, de forma quase definitiva, o gênio:

Meu conceito de Gênio. - Grandes homens são assim como grandes tempos um material explosivo, no interior do qual uma força imensa é acumulada. Histórica ou fisiologicamente, o seu pressuposto é sempre que esta força tenha se agrupado, amontoado, poupado e conservado por muito tempo para eles, - que nenhuma explosão tenha tido lugar. Se a tensão tornou-se grande demais em sua dimensão, é suficiente o estímulo mais acidental para trazer o "gênio", a "ação", o grande destino ao mundo. O que importa então o meio circundante, a época, o "espírito do tempo", a "opinião pública"! -

(...)

O grande homem é um fim; o grande tempo, a Renascença por exemplo, é um fim. O gênio - em obra, em ação - é necessariamente um desperdiçador: do fato de exaurir a si mesmo advém a sua grandeza... $O$ instinto da autoconservação está como que exposto; a pressão ultraviolenta das forças que estão se extravasando o impede de toda tentativa de proteção como esta e de todo cuidado. Costuma-se chamar isto de "sacrifício"; é célebre o seu "heroísmo" em meio a este sacrifício, sua indiferença frente ao próprio bem-estar, sua entrega a uma idéia, a uma grande idéia, à pátria: tudo malentendidos... Ele extravasa, ele transborda, ele se consome, ele não se poupa - com fatalidade, fatidicamente, involuntariamente como a irrupção de um rio por sobre as suas margens é involuntária. Mas porque se deve muito a tais explosivos, também lhes presentearam em contrapartida muitas coisas, por exemplo um tipo de moral superior... Este é mesmo o modo de ser da gratidão humana: ela compreende mal seus benfeitores. (2001c, p.45) [Negrito meu]

Pode-se considerar que Nietzsche tenha iniciado sua discussão a respeito do seu desenvolvimento do conceito de gênio na obra de juventude A origem da tragédia, com os conceitos de dionisíaco e apolíneo. Desde os gregos já havia muita discussão a respeito do que é o gênio, ou como ele se manifesta, embora tenha sido tratado à época com outros termos (como daimon). Os românticos deram um passo a mais na discussão dessa ideia de gênio, marcados fortemente pela influência de Kant. No entanto, é a partir do livro Humano, demasiado humano que Nietzsche começa a insistir na ideia de que o gênio não é um ser privilegiado, mas pode ser alcançado por qualquer pessoa que está disposta a perceber em profundidade o caráter artístico dos conceitos que fazem parte do mecanismo cognitivo do homem, tornando-se, assim, um ser autêntico e criador. Embora o gênio tenha sido visto inicialmente como um ser dotado de dons especiais e sobre-humanos. Em seguida, ele é visto como algo possível, pois pode ser identificado como algo ensinado ao longo de um percurso, tendo um aprendizado. 
ERINALDO DE OL. SALES

Nietzsche vê o gênio como alguém com um dom natural, que não pode ser apreendido. Dessa forma, a razão do criador natural deve ser trabalhada para que, na produção, o sentimento se una à razão para criar/gerar um produto de arte bela. Percebese, assim, que a faculdade da imaginação usa a matéria da natureza para criar representações (ideias) que vão além dela mesma. Nietzsche aponta uma nova perspectiva para o gênio artístico, uma vez que, para ele, é também um gênio filosófico (também podendo ser militar ou religioso). O gênio, dessa forma, é aquele que possui o "conhecimento do fundo do mundo", a intuição trágica.

No texto Schopenhauer como educador, para Nietzsche, a raiz da cultura é a aspiração dos homens em renascerem com gênio, embora haja a resistência dos homens de talento, que não possuem o gênio e impedem a geração deste. Todos os homens podem ser educados, mas nem todos têm a possibilidade de atingir o ideal schopenhauriano de gênio, ou seja, que todos trabalhem para que poucos atinjam a meta da cultura, o engendramento do gênio. Os homens de verdade são aqueles que conseguiram chegar a esse fim, a uma "existência superior": os filósofos, os artistas e os santos.

Para Nietzsche, o inimigo do filósofo é o Estado. Para ele, a filosofia deve nascer como gênio filosófico, livre do pensamento da cultura e não ensinada pelo Estado.

É no Zaratustra que Nietzsche vê o equivalente do apolíneo e do dionisíaco, pois há a busca do restabelecimento de uma noção de nobreza humana, na qual a noção de gênio aparece com necessária à vida.

\section{REFERÊNCIAS}

ABRAMS, M. H. O espelho e a lâmpada. Teoria romântica e tradição crítica. São Paulo: Editora Unesp, 2010.

KANT, Immanuel. Textos selecionados. Traduções de Tania Maria Bernkopf, Paulo Quintela, Rubens Rodrigues Torres Filho. São Paulo: Abril Cultural, 1980. Coleção Os Pensadores, v. II.

NIETZSCHE, Friedrich. Fragmentos do espólio. Primavera de 1884 a outono de 1885. Seleção, tradução e prefácio de Flávio Kothe. Brasília: Editora Universidade de Brasília, 2008.

. Estética y teoría de las artes. Prólogo, selección y traducción de Agustín Izquierdo. Madrid: Tecnos, 2007 
ERINALDO DE OL. SALES

Além do bem e do mal. Tradução de Paulo César de Souza. São Paulo: Companhia das Letras, 2005a.

Humano, demasiado humano. Tradução de Paulo César de Souza. São Paulo: Companhia das Letras, 2005b.

. Fragmentos do espólio. Junho de 1882 a inverno de 1883/1884. Seleção, tradução e prefácio de Flávio Kothe. Brasília: Editora Universidade de Brasília, 2004.

Além do bem e do mal. Tradução: Márcio Pugliesi. São Paulo: Hemus, 2001a.

O livro do filósofo. Tradução de Rubens Eduardo Ferreira Frias. São Paulo: Centauro, 2001b.

Crepúsculo dos ídolos. Tradução de Edson Bini e Márcio Pugliesi. São Paulo: Hemus, 2001c.

Obras incompletas. Tradução de Rubens Rodrigues Torres Filho. 3. ed. São Paulo: Abril Cultural, 1983. Coleção Os Pensadores.

. Aurora. s/l. Livros Rés, s.d.

. Fragmentos: 27: Verão - Outono de 1884. Tradução de Flávio Kothe. Inédito.

Vontade de potência. Disponível em:http://www.4shared.com/document/aKcVZ98C/Nietzsche__Vontade_de_potenci.htm. Acesso em: 29 jan. 2011 